\title{
Characteristics and prognostic outcome factors in elderly peritoneal dialysis patients:a prospective observational study
}

\author{
Xiaoying Ma \\ Cangzhou central hospital \\ HaiPing Xu \\ Cangzhou central hospital \\ FuYun Sun ( $D$ 13315777305@163.com )
}

\section{Research article}

Keywords: Elderly, peritoneal dialysis, death, prognosis

Posted Date: July 23rd, 2020

DOl: https://doi.org/10.21203/rs.3.rs-41395/v1

License: (1) This work is licensed under a Creative Commons Attribution 4.0 International License. Read

Full License 


\section{Abstract}

Background This study aimed to analyze the characteristics, outcomes and prognosis factors of survival in elderly peritoneal dialysis patients, so as to better understand the status of elderly peritoneal dialysis patients and improve their quality of life.

Methods This study was a prospective, observational study that included peritoneal dialysis (PD)patients.Categorizing by age, elderly group is aged $\geq 65$, younger group is aged $<65$. Clinical characteristics, survival and transferring to hemodialysis were compared between two groups.Meanwhile, risk factors of death in elderly PD patients were explored.

Results A total of 202 PD patients were enrolled, including 61 in elderly group and 141 in younger group. The comparison of baseline data between two groups: in elderly group serum albumin and normalized protein catabolic rate(nPCR) decreased, the incidence of previous cardiovascular and cerebrovascular diseases and Charlson Comorbidity Index $(\mathrm{CCl})$ were higher, the major primary disease in elderly patients was diabetic nephropathy, significant differences were found between elderly and younger group $(P<0.01)$. The mortality in elderly group was substantially higher, 27 patients (44.3\%) died in elderly group and 21 patients(14.3\%) died in younger group .The 1-year,2-year,3-year,4-year survival rate were $81.97 \%, 70.49 \%, 60.66 \%, 55.74 \%$,respectively. Cardiovascular disease was the main cause of death in elderly PD patients. Higher BMI $\mathrm{CCCl}$, and previous ischemic heart disease(IHD)were risk factors for long-term survival of elderly PD patients. Compared with the younger group, elderly patients were less likely to transfer to hemodialysis: 2 cases (3.3\%) in elderly group and 23 cases (16.3\%) in younger group. Peritonitis was primary reason for converting to hemodialysis(HD) in both two group.

Conclusions Poor nutrition, more complications and diabetic nephropathy were characteristics of elderly PD patients. High $\mathrm{BMI}, \mathrm{CCl}$ and previous IHD were independent predictors of death in elderly PD patients. Cardiovascular disease was the main cause of death in elderly PD patients, while the chief reason of transferring to hemodialysis was peritonitis.

\section{Background}

Chronic kidney disease is a global public health problem and becoming increasingly common. A survey in China found that patients with chronic kidney disease stage 3(CKD3) were about 1.2 million in 2012, and average age was 63.6 years [1]. With the development of CKD to the end stage, peritoneal dialysis has become one of the main renal replacement therapy and better choice of elderly patients with end stage renal disease,because of its small influence on hemodynamics, protection of residual renal function, low cost and simple operation [2].

Elderly PD patients have unique clinical characteristics, and incline to have multiple comorbidities, including diabetes, hypertension, cardiovascular and cerebrovascular diseases [3]. Many factors can influence the clinical outcomes of elderly PD patients such as comorbidities, complications, age and nutritional deficiency $[4,5]$. However, previous studies were mainly retrospective studies, and the influencing factors of death were variously in different countries. Some studies have shown that death is the main reason for patients to withdraw from peritoneal dialysis, age and peritonitis are the risk factors for patients to withdraw from 
peritoneal dialysis [6, 7]. However, there have been few reports about the causes of withdrawal from PD in China, especially transferring to hemodialysis.

In this study,We intended to analyze the characteristics, prognosis (death, transfer to hemodialysis) of elderly PD patients by comparing with younger group, assess the influencing factors of mortality in elderly patients.

\section{Methods}

\section{Patients and groups}

The study was approved by the ethics committee of the Cangzhou Central Hospital in Cangzhou City, Hebei Province, China. Written informed consent was attained from each patient.202 patients who received continuous ambulatory peritoneal dialysis from January 2016 to January 2017 in the Department of Nephrology of Cangzhou Central Hospital were enrolled in this prospective observational study. they did the exchange themselves only after successful training by primary nurses. Conventional PD solutions (Dianeal $1.5 \%, 2.5 \%$, or $4.25 \%$ dextrose; Baxter Healthcare, Guangzhou, China), Y-sets, and twin-bag systems were used. According to age, PD patients were divided into elderly group (age $\geq 65)$ and younger group. Elderly was defined as $\geq 65$ years old at PD initiation. Patients should met the following criteria: age $>18$ years old, first peritoneal dialysis treatment and dialysis time more than 3 months, complete data. The exclusion criteria included incomplete data, loss of follow-up, those who did not cooperate with follow-up, transferred to other dialysis centers, Additionally, we did not include patients who was diagnosed as acute renal failure, multiple organ failure. End of follow-up was defined as the day of the outcome (death or transfer to hemodialysis) or end of follow-up (January 2020).

\section{Demographic and clinical data collection}

The demographic data including genderlage, body mass index(BMI), etiological diagnosis (diabetic nephropathy, hypertensive renal damage, primary glomerular disease), peritonitis or not, bacterial culture results (gram-positive or gram-negative bacilli) were collected.We also recorded outcomes of patients: continue $\mathrm{PD}$, death, transfer to hemodialysis, kidney transplantation and time of death, reason of death, cause of

transferring to hemodialysis. The chalson index of comorbidity (CCl) was used to measure comorbidity [8]. The following variables were recorded: white blood cells(WBC), red blood cells (RBC), hemoglobin(HGB),

platelets(PLT), albumin, alanine aminotransferase(ALT), aspertate Aminotransferase (AST), total bilirubin, direct bilirubin, serum creatinine, urea nitrogen, serum calcium, potassium, sodium, ferritin, total Kt/ $\mathrm{V}$ value, residual Kt/ V, weekly creatinine clearance rate(WCcr), residual creatinine clearance rate, $\mathrm{nPCR}$, dialysis time; whether the patients used angiotensin-converting enzyme inhibitors/angiotensin receptor blocker(ACEI / ARB) drugs, ever had cerebrovascular disease, IHD, heart failure or not.

\section{Statistical analysis}

Data analyses were performed using SPSS23.0 and R 3.6.1 version. Results were expressed as mean \pm standard deviation(SD), median and interquartile ranges,, or numbers and percentages (\%), as appropriate. Kolmogorov-Smirnov test was used to examine the normality of all numeric continuous variables. Independent sample t-tests were used if with a normal distribution,while nonparametric tests (Mann-Whitney 
U test) were used to examine variables without a normal distribution,when comparing between groups. Categorical data were compared between elderly and younger groups by chi-square test. When there was only less than 5 observations in an group-outcome combination, Fisher's test was used.The Kaplan - meier survival curve was performed to investigate the difference of survival and transferring to hemodialysis between the elderly and the younger group. Multivariate Cox regression analysis was used to screen risk factor of mortality in elderly patients. Using the backward method, the entry probability was set to 0.05 , and the removal probability was set to 0.10 . R 3.6.1 version was constructed to draw nomogram map for building model to predict survival. All tests were two-sided, and $\mathrm{P}$ values $<0.05$ were considered statistically significant.

\section{Results}

\section{General characteristics of elderly patients}

We enrolled 202 PD patients, including 61 in elderly group and 141 in younger group, with a median follow-up time of 44 months. Compared with the younger group, elderly patients were more likely to have lower albumin and nPCR, more comorbidity, especially with cardiovascular and cerebrovascular diseases .Diabetic nephropathy was common in elderly group, the difference was statistically significant $(P<0.01)$. Table 1 showed the baseline characteristics of patients grouped by age(see below). 
Table 1

Basic characteristics of PD patients according to age

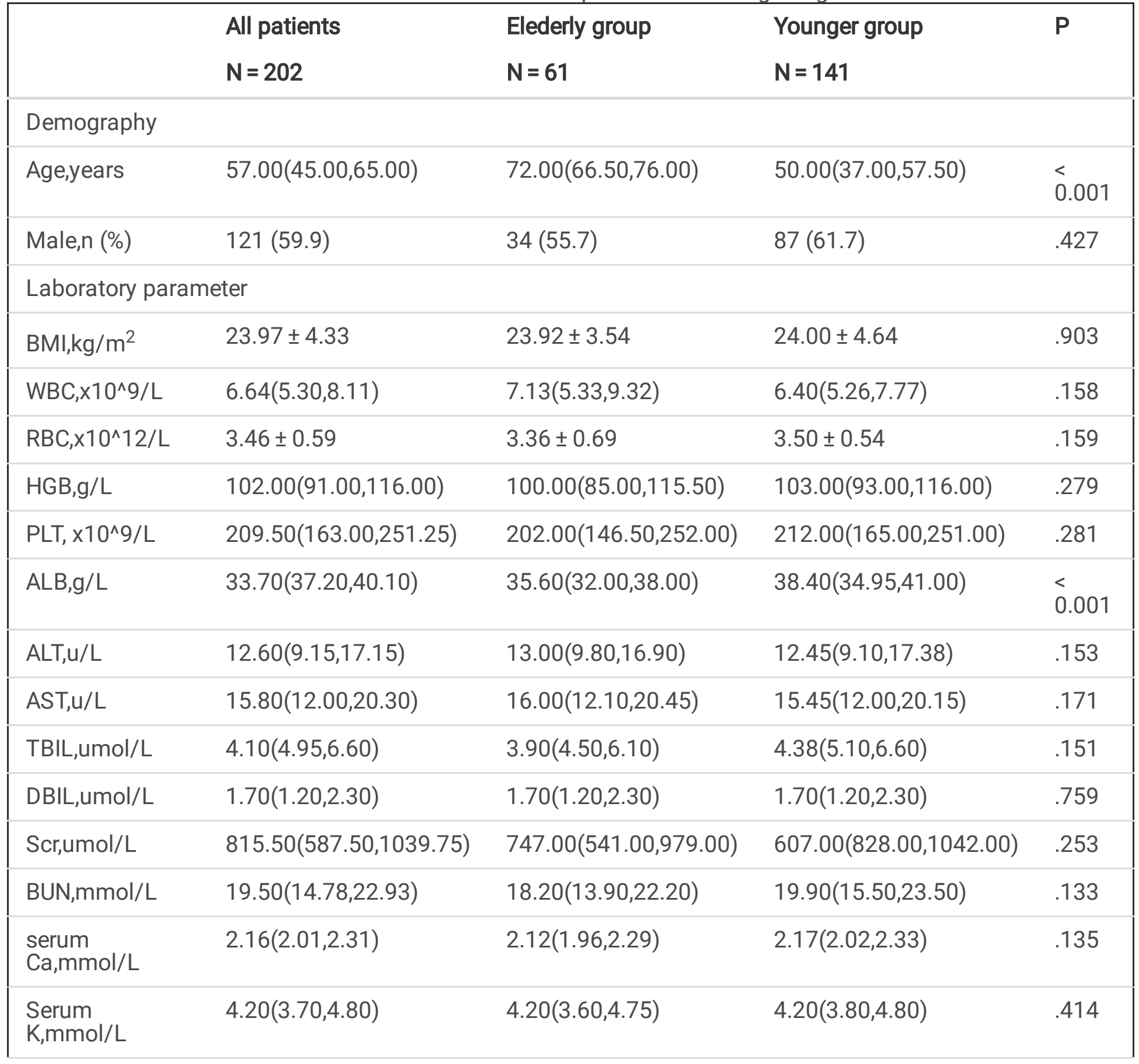

$\mathrm{PD}=$ peritoneal dialysis;BMI = body mass index $\left(\right.$ weight $/$ height $\left.^{2}\right) ; \mathrm{WBC}=$ white blood cell;

$\mathrm{RBC}=$ red blood cell; $\mathrm{PLT}=$ platelet;ALB = albumin;TBIL = tota Ibilirubin;

$\mathrm{DBIL}=$ direct bilirubin;Scr = serum creatinine; $\mathrm{BUN}=$ blood urea nitrogen;

$\mathrm{WCcr}=$ weekly creatinine clearance rate, $\mathrm{nPCR}=$ normalized protein catabolic rate;

$\mathrm{DM}=$ diabetesmellitus; $\mathrm{HRD}$ = hypertensiverenaldamage; $\mathrm{HW}$ = ischemic heart disease;

$\mathrm{HF}=$ heartfailure; $\mathrm{DN}=$ DiabeticNephropathy; $\mathrm{CG}$ = chronicglomerulonephritis; $\mathrm{HD}$ = hemodialysis 


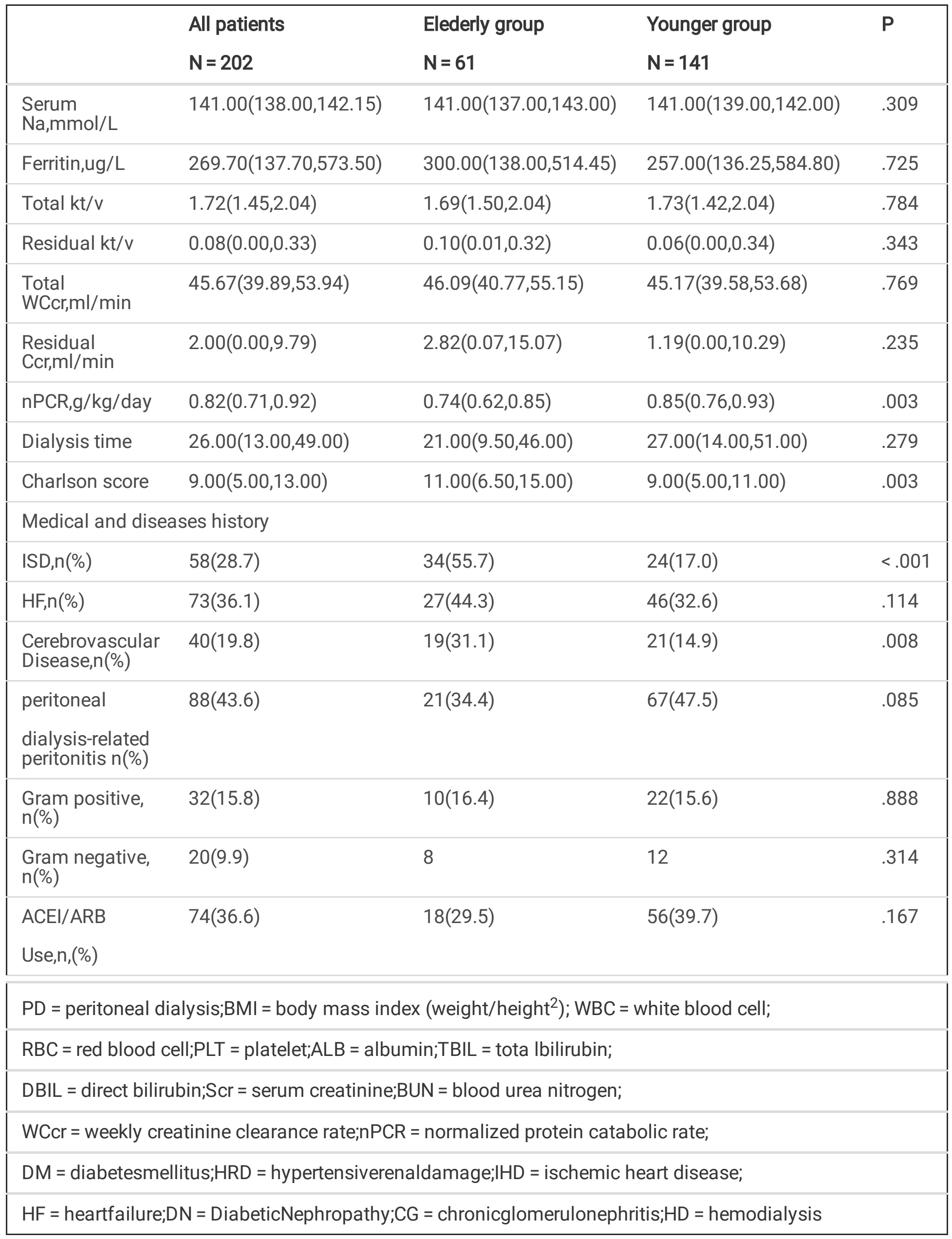




\begin{tabular}{|c|c|c|c|c|}
\hline \multirow{2}{*}{\multicolumn{2}{|c|}{$\begin{array}{l}\text { All patients } \\
\mathrm{N}=\mathbf{2 0 2}\end{array}$}} & \multirow{2}{*}{$\begin{array}{l}\text { Elederly group } \\
\mathrm{N}=61\end{array}$} & \multirow{2}{*}{$\begin{array}{l}\text { Younger group } \\
\mathrm{N}=141\end{array}$} & \multirow[t]{2}{*}{$\mathbf{P}$} \\
\hline & & & & \\
\hline \multicolumn{5}{|c|}{ Primary disease } \\
\hline $\mathrm{DN}, \mathrm{n}(\%)$ & $46(22.8)$ & $22(36.1)$ & $24(20.6)$ & .003 \\
\hline$H R D, n(\%)$ & $27(13.4)$ & 11(18.0) & 16(10.9) & .200 \\
\hline CG,n(\%) & $30(14.9)$ & $6(9,8)$ & $24(14.8)$ & .187 \\
\hline \multicolumn{5}{|c|}{$\mathrm{PD}=$ peritoneal dialysis;BMI = body mass index (weight/height $\left.{ }^{2}\right) ; \mathrm{WBC}=$ white blood cell; } \\
\hline \multicolumn{5}{|c|}{$\mathrm{RBC}=$ red blood cell;PLT = platelet;ALB = albumin;TBIL = tota Ibilirubin; } \\
\hline \multicolumn{5}{|c|}{$\mathrm{DBIL}=$ direct bilirubin;Scr = serum creatinine;BUN = blood urea nitrogen; } \\
\hline \multicolumn{5}{|c|}{$\mathrm{WCcr}=$ weekly creatinine clearance rate;nPCR = normalized protein catabolic rate; } \\
\hline \multicolumn{5}{|c|}{$\mathrm{DM}=$ diabetesmellitus; $\mathrm{HRD}$ = hypertensiverenaldamage; $\mathrm{IHD}=$ ischemic heart disease; } \\
\hline
\end{tabular}

\section{Outcomes Of Elderly Patients}

To the end of the study, 121 (59.9\%) patients continued to receive PD, 48 (23.8\%) died, 25 (12.4\%) were transferred to hemodialysis, 8 (3.9\%) received a kidney transplantation.Among elderly group, 27 (44.3\%) died, 2 (3.3\%) were transferred to hemodialysis, and $1(1.6 \%)$ received a kidney transplantation. Due to small number of kidney transplantation patients in elderly group, the following is not further discussed. Table 2 showed the oucomes of all peritoneal dialysis patients.

Table 2

Outcomes of patients

\begin{tabular}{|llll|}
\hline Outcomes & $\begin{array}{l}\text { All patients } \\
\mathbf{N = 2 0 2}\end{array}$ & $\begin{array}{l}\text { Elederly group } \\
\mathbf{N = 6 1}\end{array}$ & $\begin{array}{l}\text { Younger group } \\
\mathbf{N = 1 4 1}\end{array}$ \\
\hline Stay on PD, $\mathrm{n}(\%)$ & $121(59.9)$ & $31(50.8)$ & $90(63.8)$ \\
\hline Death, $\mathrm{n}(\%)$ & $48(23.8)$ & $27(44.3)$ & $21(14.9)$ \\
\hline $\begin{array}{l}\text { Transferred to HD, } \\
\mathrm{n}(\%)\end{array}$ & $25(12.4)$ & $2(3.3)$ & $23(16.3)$ \\
\hline $\begin{array}{l}\text { Kidney transplant, } \\
\mathrm{n}(\%)\end{array}$ & $8(3.9)$ & $1(1.6)$ & $7(5.0)$ \\
\hline
\end{tabular}

\section{Mortality Of Elderly Patients}


$27(44.3 \%)$ of elderly patients and 21 (14.3\%) of younger patients died.(Fig. 1Kaplan-Meier survival curve between elderly and younger patients)The survival time of elderly group was significantly lower than that of younger group. The 1-year $₫ 2$-year\3-year and 4-year survival rate were $81.97 \%, 70.49 \%, 60.66 \%$ and $55.74 \%$,respectively. The main cause of death in elderly PD patients was cardiovascular disease, while in younger group was infection.(Table 3 )

Table 3

Causes of Death

\begin{tabular}{|lll|}
\hline Death & \multicolumn{1}{|c|}{ Elderly group } & Younger group \\
\cline { 2 - 3 } & Cases,n(\%) & Cases,n(\%) \\
\hline Cardiovascular disease & $10(37.0)$ & $4(19.0)$ \\
\hline Cerebrovascular disease & $4(14.8)$ & $4(19.0)$ \\
\hline Infection & $3(11.1)$ & $6(28.6)$ \\
\hline Cachexia & $3(11.1)$ & $2(9.5)$ \\
\hline Other & $7(25.9)$ & $5(23.8)$ \\
\hline
\end{tabular}

\section{Transferring To Hd In Elderly Patients}

2(3.3\%)elderly PD patients, 23(16.3\%) younger group transferred to HD. Elderly patients with PD were less likely to convert to HD. Peritonitis was the chief reason for both elderly and younger PD patients to transfer to HD. (Table 4)

Table 4

Causes of transfering to HD

\begin{tabular}{|lll|}
\hline Transfer to HD & Elderly group & Younger group \\
\cline { 2 - 3 } & Cases,n(\%) & Cases,n(\%) \\
\hline Peritonitis & $2(3.3)$ & $18(12.8)$ \\
\hline Inadequate dialysis & 0 & $2(1.4)$ \\
\hline Dialysis failure & 0 & $2(1.4)$ \\
\hline Others & 0 & $1(0.7)$ \\
\hline
\end{tabular}

\section{prognostic mortality factors in elderly PD patients}

For elderly PD patients, univariate analysis Cox regression analysis indicated that $\mathrm{BMI}, \mathrm{CCl}$, previous IHD, peritonitis, dialysis time were the risk factors for the long-term survival of the elderly PD patients. BMI, $\mathrm{CCl}$ and IHD remained independent significant predictors of long-term survival of elderly PD patients by multivariate Cox regression analysis (Table 5 and Fig. 2). The impact of peritonitis,dialysis time disappeared in multivariate 
analysis. The survival model of elderly PD was established by R 3.6.1 version(Fig. 3). CCl were related to peritonitis $(r=0.471, P<0.001)$ and dialysis time $(r=0.260, P=0.043)$, these may be a confounding factor.

Table 5

Independent relative risk of death in elderly peritoneal dialysis patients

\begin{tabular}{|c|c|c|c|c|c|c|c|c|}
\hline \multicolumn{3}{|c|}{ univariate analysis } & & \multicolumn{5}{|c|}{ multivariate analysis } \\
\hline & & & $95 \% \mathrm{Cl}$ & & & & $95 \% \mathrm{Cl}$ & \\
\hline \multirow[t]{2}{*}{ Factor } & $P$ & $\mathrm{HR}$ & Lower & Upper & $P$ & $\mathrm{HR}$ & Lower & Upper \\
\hline & & & Limit & Limit & & & Limit & Limit \\
\hline BMI & .016 & 1.139 & 1.025 & 1.265 & .005 & 1.0 & 1.0 & 1.1 \\
\hline $\mathrm{CCl}$ & .018 & 1.073 & 1.012 & 1.137 & .022 & 1.1 & 1.0 & 1.2 \\
\hline ISD & .011 & 3.084 & 1.301 & 7.315 & .042 & 2.5 & 1.0 & 6.1 \\
\hline Peritonitis & .042 & 2.305 & 1.031 & 5.154 & .284 & N/A & $\mathrm{N} / \mathrm{A}$ & $\mathrm{N} / \mathrm{A}$ \\
\hline Dialysis & .089 & 1.014 & .998 & 1.030 & .310 & $\mathrm{~N} / \mathrm{A}$ & $\mathrm{N} / \mathrm{A}$ & $\mathrm{N} / \mathrm{A}$ \\
\hline Time & & & & & & & & \\
\hline
\end{tabular}

\section{Discussion}

With the aging of the population, spiraling rates of end stage renal failure have increased and the elderly needing for PD is gradually increasing [9]. In order to improve the prognosis and quality of life in elderly patients with PD, it is especially important to explore the survival status of elderly patients and actively prevent and control the risk factors.

We analyzed the general condition of the elderly patients, the reasons for withdrawal from PD therapy, and the risk factors for survival of patients, to provide guidance for improving prognosis and prolonging the survival time of patients on PD with ESRD.

Compared with the younger group, elderly group of PD patients tended to have hypoalbuminemia and low nPCR, both of which are important indicators to evaluate the nutrition of patients [10], this result was consistent with the Kholshali et al study [11]. Wang XX et al also reported that serum albumin remained lower in elderly patients [12]. In the course of PD treatment, a large number of nutrients are lost in dialysis soution, and the absorption capacity of gastrointestinal function is decreased in elderly patients, leading to malnutrition. Peritoneal dialysis does not need to establish vascular access, has little impact on hemodynamics, so elderly patients with diabetes tend to choose PD. Arteriosclerosis and the incidence of cardiovascular $\square$ cerebrovascular events is often occurred in diabetic nephropathy $[13,14]$. Age is also a risk factor of vascular calcification [15]. Some studies have shown that elderly PD patients are inclined to develop peritonitis [16], but there was no difference in the incidence of peritonitis between elderly and younger group in this study, which was consistent with a Canada study.It was reported that elderly PD patients who were 70 years old or more had no relationship with peritonitis [17], considering that elderly patients had better family 口social support and was treated with advanced antibiotics. 
In this study, the mortality of elderly patients with PD was significantly lower than that of younger patients.Age is a risk factor for survival of PD patients $[4,18]$. The $1 \varangle 2 \varangle 3 \varangle 4$ year survival rates of elderly PD patients were as follows: $81.97 \%, 70.49 \%, 60.66 \%, 55.74 \%$.A study in China found that the 1 -, 3 -, and 5-year mortality of elderly patients with PD respectively were $79 \%, 56 \%$ and $30 \%$ [19], which is generally consistent with our results.

Cardiovascular disease is the leading cause of death, $53.4 \%$ of elderly PD patients existed with cardiovascular complications in a retrospective study [19]. The USRDS data showed that cardiovascular events were the main cause of death in dialysis patients [20], which was related with the metabolic abnormalities and the increased incidence of diabetic nephropathy in elderly PD patients.

In this study,we provided evidence that high $\mathrm{BMI}$, high $\mathrm{CCl}$ and IHD were independent risk factors for predicting death in elderly PD patients. Patients with high BMI is inclined to have high risk of dialysis [21], and obesity can increase cardiovascular and cerebrovascular events, thus increasing the risk of death [22]. However, the relationship between $\mathrm{BMI}$ and survival in elderly patients with PD is controversial. Some studies found that obese PD patients lived longer than those with lower BMI [23, 24],considering that patients with lower BMI will increase protein consumption and inflammation, and high BMI can increase hemodynamic stability and the isolation of fat tissue from toxins [25]. Another study found that baseline BMI was not related to the prognosis of peritoneal dialysis [26], so more studies are needed to explore the relationship between BMI and death in elderly PD patients. As mentioned, $\mathrm{CCl}$ is an important index to evaluate the complications. Sandrine genestier et al showed that $\mathrm{CCl}$ was positively correlated with the mortality of elderly patients [27]. A retrospective analysis of 292 patients found that 2-year survival rate of elderly patients with $\mathrm{CCl}$ score $>9$ was $38 \%$, and that of patients with $\mathrm{CCl}<7$ reached 69\% [28]. Elderly PD patients often suffer with IHD, and the risk of recurrence with cardiovascular and cerebrovascular events increases [29],so elderly PD patients are at high risk of death.

In this study, peritonitis was main cause of transferring to hemodialysis in both elderly and younger patients. Minli et al. [30] and Sakaci et al. [31] also found that the main cause of turning to hemodialysis was peritonitis. Elderly patients turning to hemodialysis was smaller than that of younger patients. Elderly patients had a higher risk of peritonitis-related and all-cause mortality. In a recent study from Brazil, the only factor associated with death during peritoneal infection was older age [32],so elderly patients had no chance to transfer to HD.

This study elucidated the characteristics of elderly PD patients, the prognosis of elderly PD patients and the risk factors for predicting death, which help nephrologists better understand the characteristics of elderly PD patients and improve the prognosis of patients. However, this study has some limitations. First of all, this study is a single center, relatively small sample study, which can not represent the situation of elderly PD patients in China, additional multiple studies are needed in larger populations to confirm the conclusion of our study. In addition, we did not analyze economic and social situation of each patient.

\section{Conclusions}

In conclusion,compared with younger group, elderly PD patients had poor nutritional status, more complications, majority of diabetic nephropathy and high mortality. High BMI, high $\mathrm{CCl}$ and previous IHD events were the independent risk factors to predict mortality of elderly PD patients. Cardiovascular disease was main cause of death in elderly group. Peritonitis was major reason for transferring to HD inPD patients. 


\section{Abbreviations}

$\mathrm{PD}=$ peritoneal dialysis; $\mathrm{HD}=$ hemodialysis; $\mathrm{nPCR}=$ normalized protein catabolic rate; $\mathrm{CCl}=$ Charlson Comorbidity Index; $\mathrm{BMI}=$ body mass index; $\mathrm{WBC}=$ white blood cell; $\mathrm{RBC}=$ red blood cell;PLT = platelet; $\mathrm{ALB}$ =albumin;TBIL=totalbilirubin;DBIL=direct bilirubin;Scr=serumcreatinine; $B U N=$ blood urea nitrogen;WCcr=weekly creatinine clearance rate; $\mathrm{DM}=$ diabetesmellitus; $\mathrm{HRD}=$ hypertensive renal damage; $\mathrm{IHD}=$ ischemic heart disease; $\mathrm{HF}=$ heart failure; $\mathrm{DN}=$ = Diabetic Nephropathy; $\mathrm{CG}=$ chronic glomerulonephritis;SD=standard deviation

\section{Declarations}

\section{Ethics approval and consent to participate}

The study was approved by the ethics committee of the Cangzhou Central Hospital in Cangzhou City, Hebei Province, China. Written informed consent was attained from each patient.

\section{Consent for publication}

Not applicable

\section{Availability of data and materials}

The datasets generated and/or analyzed during the current study are not publicly available due to local regulations on the management of medical records but are available from the corresponding author on reasonable request.

\section{Conflict of interest}

None declared

\section{Funding}

Not applicable

\section{Authors' Contributions}

SF and MX: project development, data collection, and management, data analysis, manuscript writing and revising; $\mathrm{XH}$ : data collection, data analysis; $\mathrm{XH}$ : manuscript editing and revising; All authors have read and approved the manuscript.

\section{Acknowledgements}

We would like to thank the nursing staff of the PD unit for inspiration and helpful discussions.

\section{References}

1. Zhang L, Wang F, Wang L, Wang W, Liu B, Liu J, Chen M, He Q, Liao Y, Yu X et al: Prevalence of chronic kidney disease in China: a cross-sectional survey. Lancet 2012, 379(9818):815-822. 
2. Brown EA, Johansson L: Epidemiology and management of end-stage renal disease in the elderly. Nat Rev Nephrol 2011, 7(10):591-598.

3. Dimkovic NB, Prakash S, Roscoe J, Brissenden J, Tam P, Bargman J, Vas SI, Oreopoulos DG: Chronic peritoneal dialysis in octogenarians. Nephrol Dial Transplant 2001, 16(10):2034-2040.

4. Hung CC, Chang CT, Lee CC, Chen KH, Yu CC, Wu CH, Huang JY, Wu MS, Yang CW: Prognostic predictors of technique and patient survival in elderly Southeast Asian patients undergoin g continuous ambulatory peritoneal dialysis. Int J Clin Pract 2009, 63(2):254-260.

5. Weinhandl ED, Foley RN, Gilbertson DT, Arneson TJ, Snyder JJ, Collins AJ: Propensity-matched mortality comparison of incident hemodialysis and peritoneal dialysis patients. J Am Soc Nephrol 2010, 21(3):499506.

6. Mizuno M, Ito Y, Tanaka A, Suzuki Y, Hiramatsu H, Watanabe M, Tsuruta Y, Matsuoka T, Ito I, Tamai H et al: Peritonitis is still an important factor for withdrawal from peritoneal dialysis therapy in the Tokai area of Japan. Clin Exp Nephro/ 2011, 15(5):727-737.

7. Luo Q, Xia X, Lin Z, Lin J, Yang X, Huang F, Yu X: Very early withdrawal from treatment in patients starting peritoneal dialysis. Ren Fail 2018, 40(1):8-14.

8. Beddhu S, Zeidel ML, Saul M, Seddon P, Samore MH, Stoddard GJ, Bruns FJ: The effects of comorbid conditions on the outcomes of patients undergoing peritoneal dialysis. Am J Med 2002, 112(9):696-701.

9. Disney AP: Demography and survival of patients receiving treatment for chronic renal failure in Australia and Ne w Zealand: report on dialysis and renal transplantation treatment from the Australia and New Zealand Dialysis and Transplant Registry. Am J Kidney Dis 1995, 25(1):165-175.

10. Grzegorzewska A, Dobrowolska-Zachwieja A: [Comparison of indices of kinetic modelling of urea and creatinine as well as evaluation of nutrition al status of patients treated with continuous ambulatory peritoneal dialysis]. Pol Arch Med Wewn 1994, 91(6):417-426.

11. Khoshhali M, Kazemi I, Hosseini SM, Seirafian S: Relationship between trajectories of serum albumin levels and technique failure according to diabetic status in peritoneal dialysis patients: A joint modeling approach. Kidney Res Clin Pract 2017, 36(2):182-191.

12. Wang $X$, Han Q, Wang T, Tang W: Serum albumin changes and mortality risk of peritoneal dialysis patients. Int Urol Nephrol 2020, 52(3):565-571.

13. Yao Q, Lindholm B, Heimb”“1rger O: Peritoneal dialysis prescription for diabetic patients. Perit Dial Int 2005, 25 Suppl 3:S76-79.

14. Hadjadj S, Cariou B, Fumeron F, Gand E, Charpentier G, Roussel R, Kasmi AA, Gautier JF, Mohammedi K, Gourdy $\mathrm{P}$ et al: Death, end-stage renal disease and renal function decline in patients with diabetic nephropathy in F rench cohorts of type 1 and type 2 diabetes. Diabetologia 2016, 59(1):208-216.

15. Ma D, Yan H, Yang X, Yu Z, Ni Z, Fang W: Abdominal aortic calcification score as a predictor of clinical outcome in peritoneal dialysis patien ts: a prospective cohort study. BMC Nephrol 2020, 21(1):151.

16. Wu H, Ye H, Huang R, Yi C, Wu J, Yu X, Yang X: Incidence and risk factors of peritoneal dialysis-related peritonitis in elderly patients: A retrospe ctive clinical study. Perit Dial Int 2020, 40(1):26-33.

17. Nessim SJ, Bargman JM, Austin PC, Story K, Jassal SV: Impact of age on peritonitis risk in peritoneal dialysis patients: an era effect. Clinical journal of the American Society of Nephrology : CJASN2009, 
4(1):135-141.

18. Iqbal MM, Islam MN, Mansur MA, Naeem GM, Sattar H, Hossain RM, Mohsin M, Rahman MH, Rashid HU: Outcome of peritoneal dialysis and hemodialysis in elderly patients with diabetes: early experience f rom Bangladesh. Adv Perit Dial 2005, 21:85-89.

19. Joshi U, Guo Q, Yi C, Huang R, Li Z, Yu X, Yang X: Clinical outcomes in elderly patients on chronic peritoneal dialysis: a retrospective study from a si ngle center in china. Perit Dial Int 2014, 34(3):299-307.

20. US Renal Data System 2016 Annual Data Report: Epidemiology of Kidney Disease in the United States. Am J Kidney Dis 2017, 69(3s1):A4.

21. Kalantar-Zadeh K, Kopple JD: Body mass index and risk for end-stage renal disease. Ann Intern Med 2006, 144(9):701; author reply 701-702.

22. Goodkin DA, Mapes DL, Held PJ: The dialysis outcomes and practice patterns study (DOPPS): how can we improve the care of hemodialysi s patients? Semin Dia/2001, 14(3):157-159.

23. Chung SH, Lindholm B, Lee HB: Influence of initial nutritional status on continuous ambulatory peritoneal dialysis patient survival. Perit Dial Int 2000, 20(1):19-26.

24. McCusker FX, Teehan BP, Thorpe KE, Keshaviah PR, Churchill DN: How much peritoneal dialysis is required for the maintenance of a good nutritional state? Canada-USA (CANUSA) Peritoneal Dialysis Study Group. Kidney Int Supp/ 1996, 56:S56-61.

25. Park J, Ahmadi SF, Streja E, Molnar MZ, Flegal KM, Gillen D, Kovesdy CP, Kalantar-Zadeh K: Obesity paradox in end-stage kidney disease patients. Prog Cardiovasc Dis 2014, 56(4):415-425.

26. Badve SV, Paul SK, Klein K, Clayton PA, Hawley CM, Brown FG, Boudville N, Polkinghorne KR, McDonald SP, Johnson DW: The association between body mass index and mortality in incident dialysis patients. PLOS One 2014, 9(12):e114897.

27. Genestier S, Meyer N, Chantrel F, Alenabi F, Brignon P, Maaz M, Muller S, Faller B: Prognostic survival factors in elderly renal failure patients treated with peritoneal dialysis: a nin e-year retrospective study. Perit Dial Int 2010, 30(2):218-226.

28. Vrtovsnik F, Porcher R, Michel C, Hufnagel G, Queffeulou G, Mentr“| F, Mignon F: Survival of elderly patients on peritoneal dialysis: retrospective study of 292 patients, from 1982 t o 1999. Perit Dial Int 2002, 22(1):73-81.

29. Abu-Assi E, L“®pez-L“`®pez A, Gonz“çlez-Salvado V, Redondo-Di“'iguez A, Pe?a-Gil C, Bouzas-Cruz N, Raposeiras-Roub“an S, Riziq-Yousef Abumuaileq R, Garc“aa-Acu?a JM, Gonz“çlez-Juanatey JR: The Risk of Cardiovascular Events After an Acute Coronary Event Remains High, Especially During the $F$ irst Year, Despite Revascularization. Rev Esp Cardiol (Engl Ed) 2016, 69(1):11-18.

30. Li M, Yan J, Zhang H, Wu Q, Wang J, Liu J, Xing C, Zhou Y: Analysis of outcome and factors correlated with maintenance peritoneal dialysis. J Int Med Res 2019, 47(10):4683-4690.

31. Sakac T, Ahbap E, Koc Y, Basturk T, Ucar ZA, S?nang?! A, Sev?nc M, Kara E, Akgol C, Kayalar AO et al: Clinical outcomes and mortality in elderly peritoneal dialysis patients. Clinics (Sao Paulo) 2015, 70(5):363368.

32. de Moraes TP, Olandoski M, Caramori JC, Martin LC, Fernandes N, Divino-Filho JC, Pecoits-Filho R, Barretti P: Novel predictors of peritonitis-related outcomes in the BRAZPD cohort. Perit Dial Int 2014, 34(2):179- 
187.

Figures

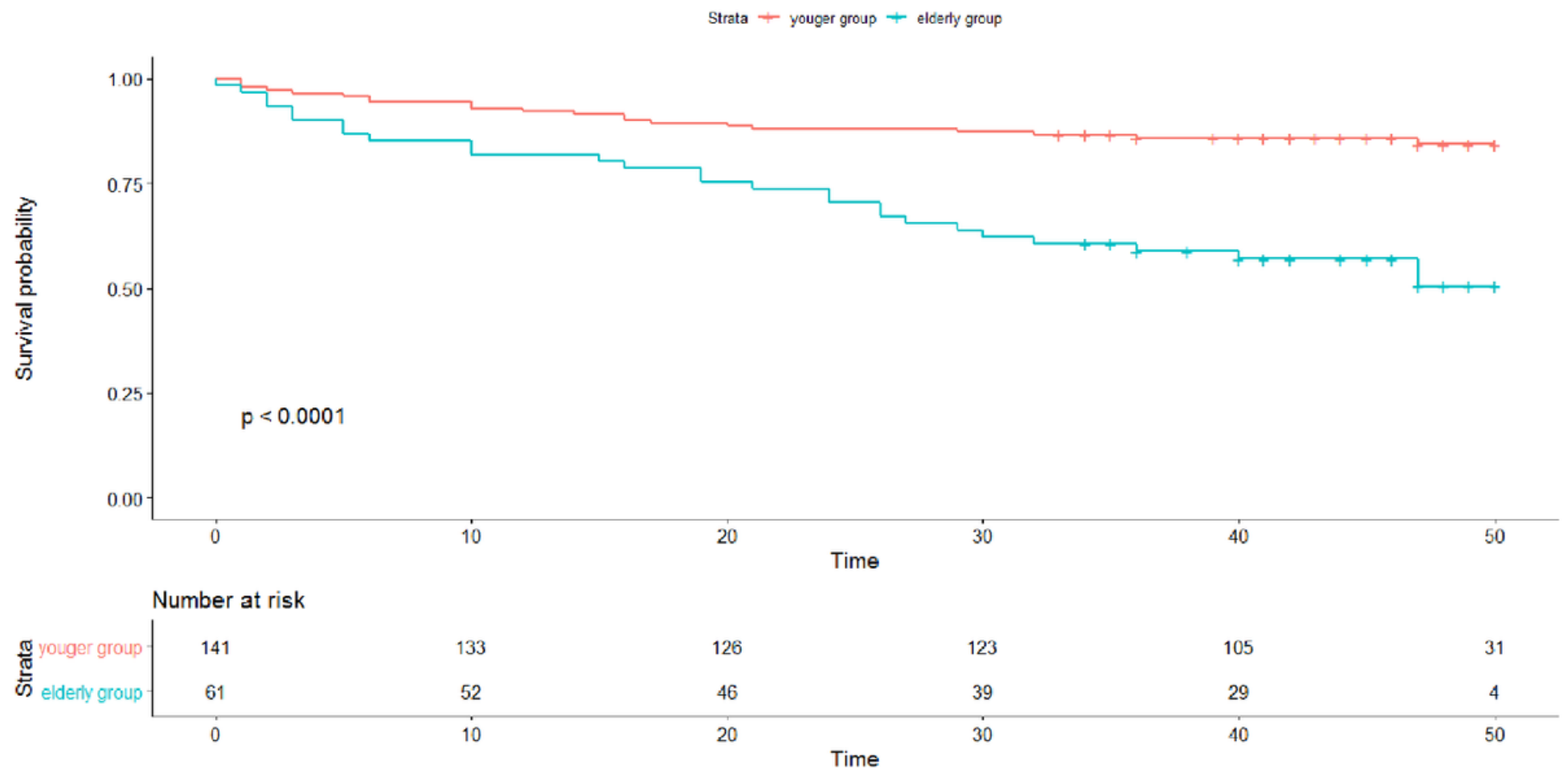

\section{Figure 1}

Kaplan-Meier survival curve according to age Time means follow-up time(months)

Hazard ratio

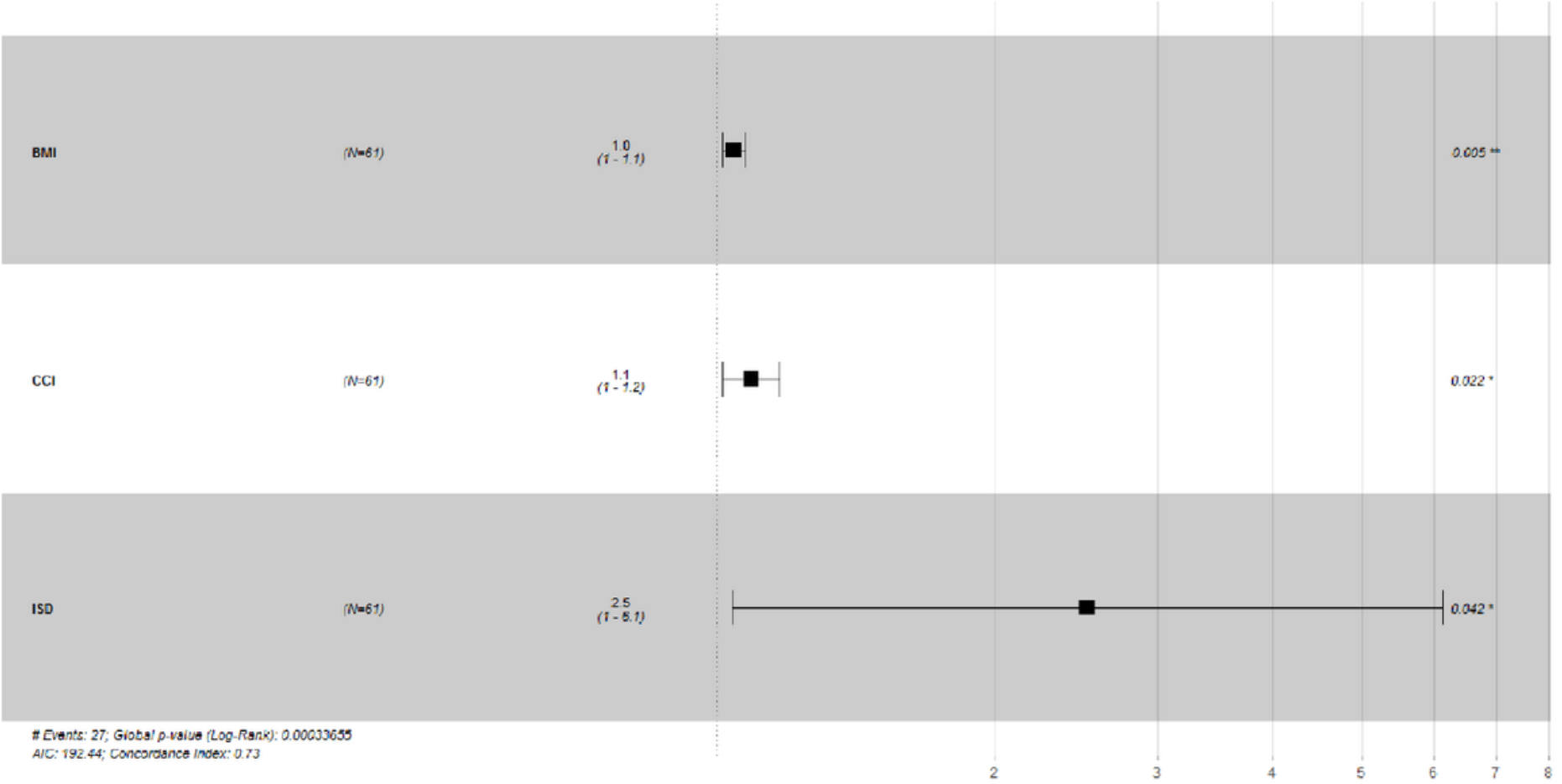


Figure 2

Independent relative risk of death in elderly peritoneal dialysis patients by multivariate analysis

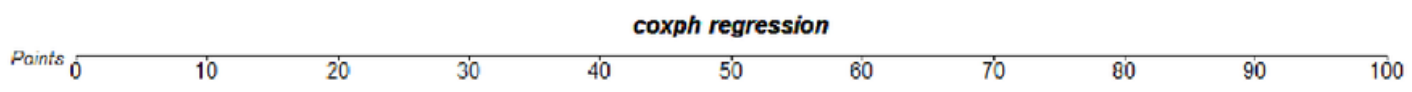

$1 \mathrm{SO}^{*}$

$\begin{array}{lllll}0.2 & 0.4 & 0.6 & 0.8 & 1\end{array}$

GCI*

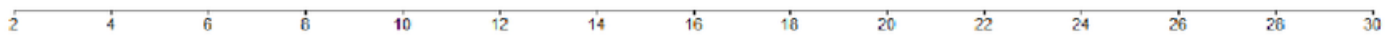

BMP*

$\begin{array}{llllll}10 & 15 & 20 & 25 & 30 & 35\end{array}$

Total-points-to-outcome nomogram:

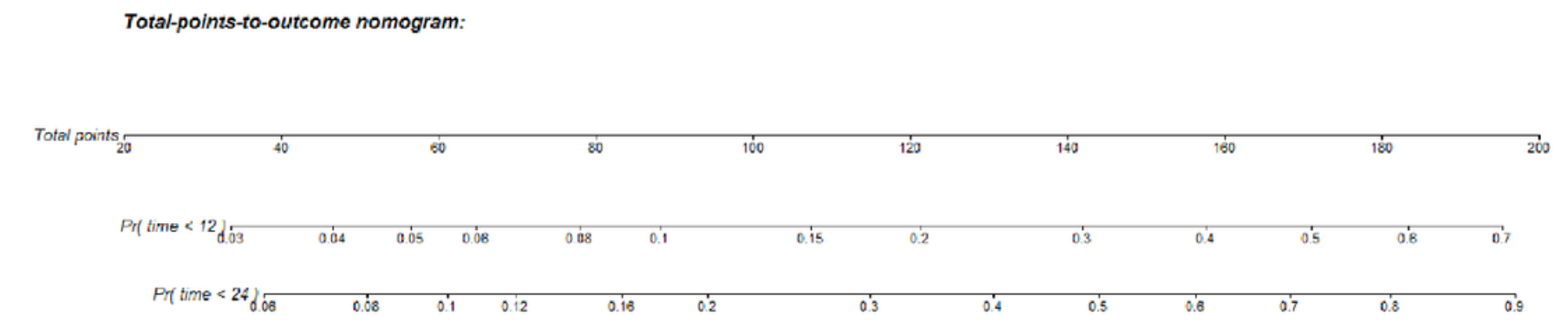

Figure 3

Joint modeling for prognostic predictors of survival in elderly patients

\section{Supplementary Files}

This is a list of supplementary files associated with this preprint. Click to download.

- STROBEchecklist.docx 